This is the post reviewed version of the following article: Szigethy, G. and Raymond, K. N. (2011), The Influence of Linker Geometry in Bis(3-hydroxy- $N$-methyl-pyridin-2-one) Ligands on Solution Phase Uranyl Affinity. Chemistry - A European Journal, 17: 1818-1827. doi: 10.1002/chem.201002372, which has been published in final form at http://onlinelibrary.wiley.com/doi/10.1002/chem.201002372

\title{
The Influence of Linker Geometry in bis(3-hydroxy-N-methyl-pyridin-2-one) Ligands on Solution Phase Uranyl Affinity ${ }^{[1]}$
}

\author{
Dr. Géza Szigethy, ${ }^{[\mathrm{a}]}$ Prof. Dr. Kenneth N. Raymond ${ }^{[]^{*}}$
}

[a] Chemical Sciences Division, Lawrence Berkeley National Laboratory, Berkeley, CA 94720 (USA), E-mail: raymond@socrates.berkeley.edu

Fax: (510) 486-5283

Department of Chemistry, University of California at Berkeley, Berkeley, CA 94720-1460 (USA)

Series title: "Specific Sequestering Agents for the Actinides."

Previous paper in series: G. Szigethy, K. N. Raymond, Inorg. Chem. 2010, 49, 67556765.

Supporting information for this article is available on the WWW under http://dx.doi.org/10.1002/chem.2010xxxxx. It contains experimental procedures for the synthesis of bis-Me-3,2-HOPO ligands, X-ray diffraction collection and refinement details, conformational analysis of $\mathrm{UO}_{2}\left(\mathbf{L}^{\mathbf{9}}\right)(\mathrm{DMSO})$, reversibility analyses, UV-visible titration spectra, and speciation diagrams for uranyl titrations. CCDC-783329 contains the supplementary crystallographic data for this paper. These data can be obtained free of charge from The Cambridge Crystallographic Data Centre via www.ccdc.cam.ac.uk/data_request/cif. 
This is the post reviewed version of the following article: Szigethy, G. and Raymond, K. N. (2011), The Influence of Linker Geometry in Bis(3-hydroxy- $N$-methyl-pyridin-2-one) Ligands on Solution Phase Uranyl Affinity. Chemistry - A European Journal, 17: 1818-1827. doi: 10.1002/chem.201002372, which has been published in final form at http://onlinelibrary.wiley.com/doi/10.1002/chem.201002372

Abstract: Seven water-soluble, tetradentate bis(3-hydroxy-N-methyl-pyridin-2-one) (bisMe-3,2-HOPO) ligands were synthesized that vary only in linker geometry and rigidity. Solution phase thermodynamic measurements were conducted between $\mathrm{pH} 1.6$ and $\mathrm{pH}$ 9.0 to determine the effects of these variations on proton and uranyl cation affinity. Proton affinity decreases by introduction of the solubilizing triethylene glycol group as compared to un-substituted reference ligands. Uranyl affinity was found to follow no discernable trends with incremental geometric modification. The butyl-linked 4Li-Me3,2-HOPO ligand exhibited the highest uranyl affinity, consistent with prior in vivo decorporation results. Of the rigidly-linked ligands, the o-phenylene linker imparted the best uranyl affinity to the bis-Me-3,2-HOPO ligand platform.

\section{Introduction}

The approach of rational ligand design towards targeted ion chelation seeks to match ligand traits with the geometric and thermodynamic preferences of a target ion. ${ }^{[2]}$ Modifiable ligand properties include ligand geometry, hard/soft character of coordinating atoms, ligand denticity, and geometric pre-organization. Optimization of these design characteristics is observed in bacterial ferric ion shuttling mechanisms, ${ }^{[3,4]}$ but is also central to synthetic compounds applied in many different selective extraction/removal applications such as heavy metal decorporation, ${ }^{[5,6]}$ and iron overload treatment. ${ }^{[7-9]}$ Applying rationally-designed ligands towards actinide science is of particularly great interest as nuclear power becomes an attractive carbon-free energy alternative, and the associated risk of environmental and biological exposure to actinides increases.

Unique to the early actinides is the class of linear dioxo cations (actinyls, $\mathrm{AnO}_{2}{ }^{\mathrm{n}+}$ ) adopted by uranium, neptunium, and plutonium in their +5 or +6 oxidation states. Actinyls pose an unusual challenge to the practice of rational ligand design because, while they display hard Lewis acidity typical of the $f$-elements, they maintain nearlinearity in all their known complexes, with the largest distortions of just over $11^{\circ}$ occurring only in the presence of very sterically demanding ligands. ${ }^{[10]}$ Unlike most transition metal dioxo cations, ligands coordinate to actinyl cations almost exclusively in a plane perpendicular to the $\mathrm{An}=\mathrm{O}$ bonds with deviations from this behavior again only occurring in sterically congested complexes. ${ }^{[11]}$ The equatorial coordination plane displays little to no orbital-dictated directionality, with observed coordination geometries ranging from trigonal- through hexagonal-planar, depending on ligand sterics and chelating ability. ${ }^{[12-15]}$ Additionally, the terminal oxo atoms of the actinyl cations (especially in their +6 oxidation state) display poor Lewis basicity, although they have been observed to interact with metal cations in the solid state. ${ }^{[12,14,16-20]}$

The uranyl cation $\left(\mathrm{UO}_{2}{ }^{2+}\right)$ is the most common actinyl species studied because uranium is the second most abundant naturally-occuring actinide as well as the one most frequently employed in nuclear power generation. ${ }^{[21]}$ Additionally, the uranyl cation is the most stable form for uranium in oxidizing environments or in vivo. Several different approaches have been used to design uranyl-selective ligands; rigid poly-pyrrole macrocycles have utilized their pre-arranged geometry to form planar uranyl chelates, ${ }^{[22]}$ apically-oriented molecules have introduced Lewis acids in the vicinity of one uranyl oxo 
This is the post reviewed version of the following article: Szigethy, G. and Raymond, K. N. (2011), The Influence of Linker Geometry in Bis(3-hydroxy- $N$-methyl-pyridin-2-one) Ligands on Solution Phase Uranyl Affinity. Chemistry - A European Journal, 17: 1818-1827. doi: 10.1002/chem.201002372, which has been published in final form at http://onlinelibrary.wiley.com/doi/10.1002/chem.201002372

moiety, ${ }^{[23,24]}$ while some fold-over macrocyles have achieved both these goals simultaneously. ${ }^{[25,26]}$

Significant effort has been dedicated towards the development of efficient uranyl cation extraction agents for both analytical and industrial applications, but these studies typically address low $\mathrm{pH}$ conditions typical of industrial metal separations technologies. ${ }^{[27,28]}$ However, the rational development of biological decorporation agents necessarily requires studying the efficacy of uranyl chelation at in vivo $\mathrm{pH}$ ranges which are higher than those of industrial/remediation applications. Examples of biologically relevant investigations include that of Czerwinski and co-workers that addresses uranyl speciation with the naturally-occuring siderophore desferrioxamine (DFO) ${ }^{[29]}$ as well as those by Durbin and co-workers that examine the in vivo decorporating ability of polybidentate catecholamides and their structural analogs towards the uranyl and transuranic cations. $^{[30-33]}$ These latter studies revealed that 4- or 5-carbon linear linkers provided optimal decorporating ability to poly-bidentate ligands, but the detailed thermodynamic rationale for this result is relatively unexplored.

Recent work in our group has focused on optimizing the equatorial geometric agreement between the uranyl cation and bis(3-hydroxy-N-methyl-pyridin-2-one) (bisMe-3,2-HOPO) ligands utilizing linker molecules of varying geometries. ${ }^{[34-36]}$ The Me$3,2-\mathrm{HOPO}$ moiety is a bidentate, structural analog to the catecholamide group which binds via hard Lewis basic oxygens and is thus ideal for chelating the strong Lewis-acidic actinide ions. While short linkers best preserve intramolecular hydrogen bonds typical of catecholamide ligands, ${ }^{[36]}$ structural comparisons of the uranyl complexes against that with Pr-Me-3,2-HOPO ( $\mathbf{L}^{\mathbf{1}} \mathbf{H}$, Figure 1) illustrated that the butyl-linked ligand 4Li-Me$3,2-\mathrm{HOPO}$ provided the most favorable geometry for uranyl chelation of the linearlylinked, tetradentate ligands (nLi-Me-3,2-HOPO, where " $\mathrm{n}$ " is the number of carbon atoms in the linker and "Li" stands for "linear"). ${ }^{[36]}$ Of the rigidly-linked ligands explored, the 3,4-thiophene, o-phenylene, $\alpha, \alpha^{\prime}-m$-xylene, and 1,8-fluorene linkers (Figure 1) showed the most favorable uranyl coordination geometries; the former two contain very short linkers, while the latter two contain the longest linkers investigated. ${ }^{[35]}$ These results raise the question of whether favorable geometry (optimized in short and long linker lengths) or intramolecular hydrogen bonding (optimized in short linkers) is most important in determining uranyl affinity.

Solution phase titrations were carried out with bis-Me-3,2-HOPO ligands to determine and compare their uranyl affinities. Unfortunately, the bis-Me-3,2-HOPO ligands previously synthesized are not soluble enough in water to enable such measurements, prompting the design and synthesis of water-soluble bis-Me-3,2-HOPO ligands $\mathbf{L}^{2} \mathbf{H}_{\mathbf{2}}-\mathbf{L}^{\mathbf{8}} \mathbf{H}_{\mathbf{2}}$ (Figure 2). These ligands incorporate linkers that are structurally analogous to previous ligands, but which also contain a methyl-protected triethyleneglycol moiety to promote water solubility, enabling quantification of their uranyl affinities.

\section{Results and Discussion}

Ligand Design and Synthesis. Water solubility was imparted to the bis-Me-3,2HOPO ligands by introduction of the methyl-protected triethyleneglycol moiety $(3,6,9-$ trioxa-decane) referred to hereon as PEG. This solubilizing group carries no charge in the 
This is the post reviewed version of the following article: Szigethy, G. and Raymond, K. N. (2011), The Influence of Linker Geometry in Bis(3-hydroxy- $N$-methyl-pyridin-2-one) Ligands on Solution Phase Uranyl Affinity. Chemistry - A European Journal, 17: 1818-1827. doi: 10.1002/chem.201002372, which has been published in final form at http://onlinelibrary.wiley.com/doi/10.1002/chem.201002372

$\mathrm{pH}$ range investigated here, and thus does not influence the charge of the resultant ligands at varying $\mathrm{pH}$. Uranyl affinity for poly-ether coordination is conveniently poor compared to other neutral Lewis bases, as evidenced by the anhydrous conditions necessary for synthesizing crown-ether inclusion complexes of the uranyl cation. ${ }^{[37]}$ Thus, coordinative interference by the PEG group is unlikely in these titration studies.

However, the location of the PEG substitution is of great concern because it can feasibly affect ligand uranyl affinity in two ways: 1) by inductively influencing the HOPO ring electronics, thereby affecting proton and uranyl affinity of the ligands, and 2) by introducing an additional steric influence, resulting in a solution phase structure significantly different from that seen in prior crystallographic analyses. ${ }^{[35,36]}$ The Me-3,2HOPO moiety is inert towards further substitution, relegating PEG substitution to the linker moieties. Due to the extended electronic conjugation in ligands containing 3,4thiophene and o-phenylene linkers $\left(\mathbf{L}^{6} \mathbf{H}_{2}\right.$ and $\left.\mathbf{L}^{7} \mathbf{H}_{2}\right)$, electronic effects on the Me-3,2HOPO moiety are unavoidable upon substitution at any position on the linker moiety. Such inductive influences will be minimal in the ligands containing the linear $\mathrm{nLi}$ - and $\alpha, \alpha^{\prime}-m$-xylene backbones $\left(\mathbf{L}^{2} \mathbf{H}_{\mathbf{2}}\right.$ through $\mathbf{L}^{5} \mathbf{H}_{\mathbf{2}}$ and $\mathbf{L}^{\mathbf{8}} \mathbf{H}_{\mathbf{2}}$ ) because the methylene linkers are not conjugated to the Me-3,2-HOPO moieties.

In addition to electronic influences, the potential steric consequences of PEG substitution become significant when the backbone is either small or contains only nonideal positions upon which to introduce the PEG group. Specifically, steric interference with the amide linkers of the Me-3,2-HOPO moiety is of great concern because intramolecular hydrogen bonding involving the amide proton is a significant interaction in HOPO and more generally in catecholamide ligands. ${ }^{[38]}$ Of particular concern is substitution on the 3,4-thiophene linker, which is relegated only to the 2- and 5-positions, the steric consequence of which is the formation of dimers of the form $\left[\mathrm{UO}_{2} \mathrm{~L}_{2}(\text { solv. })\right]_{2}$ as opposed to the mononuclear uranyl species seen with the unsubstituted 3,4-thiophene-bisMe-3,2-HOPO ligand. ${ }^{[34]}$ Because the available substitution positions on the 2Li linker are adjacent to the linking amides and cannot avoid some influence on the proton and/or uranyl affinity in $\mathbf{L}^{2} \mathbf{H}_{\mathbf{2}}$, the PEG moiety was introduced at the same position on the $3 \mathrm{Li}$, $4 \mathrm{Li}$, and $5 \mathrm{Li}$ linkers to make affinity comparisons at least internally consistent between ligands $\mathbf{L}^{2} \mathbf{H}_{\mathbf{2}}-\mathbf{L}^{5} \mathbf{H}_{\mathbf{2}}$.

Substitution on the $\alpha, \alpha^{\prime}-m$-xylene backbone in $\mathbf{L}^{8} \mathbf{H}_{\mathbf{2}}$ contains perhaps the most ideal PEG location of the ligands investigated. Firstly, the PEG moiety is located four carbons from the linking amide nitrogens, ensuring minimal steric effects, and secondly, the PEG group is electronically isolated from the HOPO moieties due to the presence of the methylene spacers between the phenyl ring and the HOPO amides. Thus, it is expected that the behavior of ligand $\mathbf{L}^{8} \mathbf{H}_{2}$ in solution will most closely resemble that of its unsubstituted analog compared to the other PEG-bis-Me-3,2-HOPO ligands.

Absent from the backbones illustrated in Figure 2 is the 1,8-fluorene moiety that was shown to provide a very good geometric match to the uranyl cation coordination preferences while displaying a degree of ligand pre-organization. ${ }^{[35]}$ Unfortunately, the tremendous insolubility imparted on bis-Me-3,2-HOPO ligands by the fluorene backbone cannot be undone by solubilizing group substitution due to synthetic impracticality and the natural electrophillic substitution behavior of fluorene and its structural analog 
This is the post reviewed version of the following article: Szigethy, G. and Raymond, K. N. (2011), The Influence of Linker Geometry in Bis(3-hydroxy- $N$-methyl-pyridin-2-one) Ligands on Solution Phase Uranyl Affinity. Chemistry - A European Journal, 17: 1818-1827. doi: 10.1002/chem.201002372, which has been published in final form at http://onlinelibrary.wiley.com/doi/10.1002/chem.201002372

dibenzofuran; thus a soluble 1,8-diaminofluorene-linked bis-Me-3,2-HOPO ligand was not pursued.

Structural Consequence of PEG Substitution in $\mathbf{L}^{7} \mathbf{H}_{2}$. The geometric and electronic consequences of PEG substitution on the 3,4-thiophene and o-phenylene linkers must be addressed due to the extended conjugation possible through the aromatic linkers. Thioalkyl substitution on the 3,4-thiophene linker in bis-Me-3,2-HOPO ligands is know to result in sterically-induced $\left[\mathrm{UO}_{2}(\mathrm{~L}) \text { (solv.) }\right]_{2}$ dimer formation, ${ }^{[34]}$ a behavior that ligand $\mathbf{L}^{8} \mathbf{H}_{2}$ will certainly duplicate. In contrast, the PEG groups in $\mathbf{L}^{7} \mathbf{H}_{2}$ are meta to the amide nitrogens, and the ligand is thus expected to maintain planarity upon uranyl chelation, with the resultant conjugation allowing for a potentially increased inductive influence by the PEG substitution. To investigate the presence/severity of such an effect, the propoxy-substituted ligand $\mathbf{L}^{9} \mathbf{H}_{2}$ and its uranyl complex were synthesized (Figure 3). Crystallographic parameters for this structure are listed in Table 1.

The $\mathrm{UO}_{2}\left(\mathbf{L}^{9}\right)(\mathrm{DMSO})$ crystal structure displays the expected mononuclear speciation seen with other bis-Me-3,2-HOPO ligands, ${ }^{[35,}$ 36] with a pentagonal planar uranyl coordination geometry provided on four points by $\left(\mathbf{L}^{\mathbf{9}}\right)^{2-}$, and a fifth site occupied by a DMSO oxygen. Significantly, the propoxy substituents are situated away from the amide linkers, so it can be assumed that PEG groups in $\mathbf{L}^{7} \mathbf{H}_{\mathbf{2}}$ will not impart significant steric influence on the resultant uranyl complex. The equatorial $\mathrm{U}-\mathrm{O}_{\text {phenol }}$ and $\mathrm{U}-\mathrm{O}_{\text {amide }}$ bond lengths are 2.34(1) $\AA$ and 2.42(2) $\AA$, respectively, which are statistically identical to the similar equatorial $\mathrm{U}-\mathrm{O}$ bond lengths in the uranyl complex with the unsubstituted $o$ phenylene-Me-3,2-HOPO ligand. ${ }^{[35]}$ As Figure 3 illustrates, the backbone aryl group is not co-planar with the HOPO moieties due to a torsion in the linking amide moieties. The $\mathrm{C}_{\text {ring }}-\mathrm{N}_{\text {amide }}$ torsion angles of $156^{\circ}$ and $167^{\circ}$ presumably relieve a potential close contact between the amide protons in the metal-chelating form that is observed to a similar extent in the unsubstituted uranyl complex (torsions of $148^{\circ}$ and $157^{\circ}$ ), ${ }^{[35]}$ as well as in the $\mathrm{Eu}(\mathrm{III})$ complex with the structurally-similar o-phenylene-1,2-HOPO ligand (torsions of $157^{\circ}, 159^{\circ}$, and $\left.169^{\circ}\right) \cdot{ }^{[39]}$ Thus, while there are slight differences in the co-planarity of the $\mathrm{UO}_{2}\left(\mathbf{L}^{\mathbf{9}}\right)(\mathrm{DMSO})$ crystal structure from its unsubstituted complex (see Supporting Information), the overall structure is similar to that with its unsubstituted analog.

To assess the potential electronic effect of PEG substitution on the $o$-phenylene linker in $\mathbf{L}^{7} \mathbf{H}_{2}$ the ${ }^{1} \mathrm{H}$ NMR resonances of the amide protons in free $\mathbf{L}^{\mathbf{9}} \mathbf{H}_{\mathbf{2}}$ and its uranyl complex can be compared against those in the unsubtituted o-phenylene-Me-3,2-HOPO ligand and its uranyl complex. ${ }^{[35]}$ The amide proton chemical shifts of free $\mathbf{L}^{9} \mathbf{H}_{\mathbf{2}}$ are 0.13 ppm upfield of that in o-phenylene-Me-3,2-HOPO, suggesting some electronic donation into the aryl linker upon alkoxy substitution. However, these same resonances are only $0.06 \mathrm{ppm}$ upfield of the unsubstituted ligand once coordinated to the uranyl cation. The similarity in these values suggests that the inductive effects of alkoxy substitution on the 3- and 4-positions of the $o$-phenylene linker are minor, especially upon uranyl chelation. Additionally, the amide chemical shifts in $\mathbf{L}^{7} \mathbf{H}_{2}$ are $0.01 \mathrm{ppm}$ shifted from $\mathbf{L}^{\mathbf{9}} \mathbf{H}_{\mathbf{2}}$, indicating a near-identical inductive effect. The crystallographic and NMR comparisons thus indicate that the PEG substitution in $\mathbf{L}^{7} \mathbf{H}_{\mathbf{2}}$ should have a relatively insignificant impact on the resultant uranyl complex geometry either through steric or inductive processes. 
This is the post reviewed version of the following article: Szigethy, G. and Raymond, K. N. (2011), The Influence of Linker Geometry in Bis(3-hydroxy- $N$-methyl-pyridin-2-one) Ligands on Solution Phase Uranyl Affinity. Chemistry - A European Journal, 17: 1818-1827. doi: 10.1002/chem.201002372, which has been published in final form at http://onlinelibrary.wiley.com/doi/10.1002/chem.201002372

Solution Thermodynamics. In the presence of dissolved metal ion $\left(\mathrm{M}^{\mathrm{a}+}\right)$ and protonated ligand $\left(\mathrm{LH}_{n}\right.$, where $\mathrm{L}$ is a ligand with $n$ removable protons), a $\mathrm{pH}$-dependent metal-ligand complex of general formula $\mathrm{M}_{m} \mathrm{~L}_{l} \mathrm{H}_{h}$ forms according to the equilibrium shown in Equation 1. The relative amount of each species in solution is determined by Equation 2, the rearrangement of which provides the standard formation constant notation of $\log \beta_{m l h}$ (Equation 3). The $\log \beta_{m l h}$ value describes a cumulative formation constant, but a stepwise formation constant $(\log \mathrm{K})$ can be calculated from $\log \beta_{\text {mlh }}$ values using Equation 4. When addressing protonation constants, the stepwise formation constants are commonly reported as dissociation constants $\left(-\log \mathrm{K}\right.$, or $\left.\mathrm{pK}_{\mathrm{a}}\right)$.

Eq. 1: $m \mathrm{M}^{\mathrm{a}+}+l \mathrm{~L}^{\mathrm{b}-}+h \mathrm{H}^{+} \stackrel{\beta_{m l h}}{\rightleftharpoons} \mathrm{M}_{m} \mathrm{~L}_{l} \mathrm{H}_{h}^{(m \mathrm{a}-l \mathrm{~b}+h)+}$

Eq. 2: $\left[\mathrm{M}_{m} \mathrm{~L}_{l} \mathrm{H}_{h}\right]=\beta_{m l h}\left([\mathrm{M}]^{m}[\mathrm{~L}]^{l}[\mathrm{H}]^{h}\right)$

Eq. 3: $\log \beta_{m l h}=\log \left\{\left(\left[\mathrm{M}_{m} \mathrm{~L}_{l} \mathrm{H}_{h}\right]\right) /\left([\mathrm{M}]^{m}[\mathrm{~L}]^{l}[\mathrm{H}]^{h}\right)\right\}$

Eq. 4: $\log \mathrm{K}_{01 n}=\log \left\{\left(\left[\mathrm{LH}_{n}\right]\right) /\left(\left[\mathrm{LH}_{n-1}\right][\mathrm{H}]\right)\right\}=\log \left\{\left(\beta_{01 n} / \beta_{01(n-1)}\right\}=\log \beta_{01 n}-\log \beta_{01(n-1)}\right.$

Because bis-Me-3,2-HOPO ligands are diprotic and require deprotonation for metal chelation, their affinity for any metal is necessarily $\mathrm{pH}$ dependent (Scheme 1). Although the most common $\mathrm{pH}$ for biological applications is that of blood serum, or $\mathrm{pH} 7.4$, it is also desirable to investigate the uranyl affinity of bis-Me-3,2-HOPO ligands in acidic and caustic media, as such conditions are encountered in industrial or storage tank waste remediation applications. ${ }^{[40,41]}$

Proton Titrations/Affinity. Protonation constants of ligands $\mathbf{L}^{2} \mathbf{H}_{\mathbf{2}}-\mathbf{L}^{\mathbf{8}} \mathbf{H}_{\mathbf{2}}$ were determined using potentiometric titrations at about $150-200 \mu \mathrm{M}$ ligand concentration. As a point of comparison for ligands $\mathbf{L}^{2} \mathbf{H}_{2}-\mathbf{L}^{5} \mathbf{H}_{2}$, the protonation constants for the previously reported $2 \mathrm{Li}$ - and $4 \mathrm{Li}-\mathrm{Me}-3,2-\mathrm{HOPO}$ ligands ${ }^{[36]}$ were also measured, but were performed spectrophotometrically due to their lower solubility at about $50 \mu \mathrm{M}$ ligand concentration. A 5\% starting DMSO concentration in all protonation titrations was required for consistency with uranyl titration conditions. Data were analyzed as described in the Experimental Section and the resultant $\mathrm{pK}_{\mathrm{a}}$ values are listed in Table 2. The sum of the $\mathrm{pK}_{\mathrm{a}}$ values $\left(\Sigma \mathrm{pK} \mathrm{K}_{\mathrm{a}}\right)$ is also listed, which corresponds to the $\log \beta_{012}$ formation constant and is a general measure of ligand acidity, with lower $\Sigma \mathrm{pK}_{\mathrm{a}}$ values indicating a more acidic ligand.

One trend visible in Table 2 is that linearly-linked ligands with shorter linkers (smaller $n$ ) have lower $\Sigma \mathrm{pK}_{\mathrm{a}}$ values than those with longer linkers. This general trend is seen in ligands $\mathbf{L}^{\mathbf{2}} \mathbf{H}_{\mathbf{2}}-\mathbf{L}^{5} \mathbf{H}_{\mathbf{2}}(\Delta \Sigma \mathrm{pK} \mathrm{a} \approx 0.7)$ as well as between $2 \mathrm{Li}$ - and 4Li-Me-3,2HOPO $\left(\Delta \Sigma \mathrm{pK}_{\mathrm{a}} \approx 0.5\right)$. A second trend is that substitution of the PEG moiety on the linear linkers via an amide linker also lowers the $\Sigma \mathrm{pK}_{\mathrm{a}}$ compared to the unsubstituted ligands, as evidenced by comparing 2Li-Me-3,2-HOPO against $\mathbf{L}^{2} \mathbf{H}_{\mathbf{2}}(n=2)$ and 4Li-Me-3,2HOPO against $\mathbf{L}^{4} \mathbf{H}_{2}(n=4)$. This latter trend is primarily caused by a drop in $\mathrm{pK}_{\mathrm{a} 1}$ $\left(\Delta \mathrm{pK}_{\mathrm{a} 1, \max } \approx 0.7\right)$, but also affects the $\mathrm{pK}_{\mathrm{a} 2}$ values $\left(\Delta \mathrm{pK}_{\mathrm{a} 2, \max } \approx 0.4\right)$. The drop in $\Sigma \mathrm{pK}_{\mathrm{a}}$ upon $\mathrm{PEG}$ substitution $(\Delta \Sigma \mathrm{pK} \mathrm{a} / \mathrm{PEG} \approx 1.1)$ is more significant than that accompanying 
This is the post reviewed version of the following article: Szigethy, G. and Raymond, K. N. (2011), The Influence of Linker Geometry in Bis(3-hydroxy- $N$-methyl-pyridin-2-one) Ligands on Solution Phase Uranyl Affinity. Chemistry - A European Journal, 17: 1818-1827. doi: 10.1002/chem.201002372, which has been published in final form at http://onlinelibrary.wiley.com/doi/10.1002/chem.201002372

incremental shortening of the linker lengths (average $\Delta \Sigma \mathrm{pK}_{\mathrm{a}} / n \approx 0.23$ ). However, in both these trends, it can be assumed that the decrease in $\mathrm{pK}_{\mathrm{a}}$ arises from enhanced stabilization of the deprotonated phenolate oxygen, since the electronics of the HOPO moiety remain roughly constant in ligands $\mathbf{L}^{2} \mathbf{H}_{2}-\mathbf{L}^{8} \mathbf{H}_{2}$.

The intramolecular hydrogen bond stabilization of phenolates by ortho amide protons are well established and is illustrated in Figure 4(a) as it applies to Me-3,2-HOPO moieties. ${ }^{[38]}$ However, the trends observed in Table 2 suggest that additional hydrogen bond interactions become significant upon shortened linker length (smaller $n$ ) or PEG moiety introduction. The drop in $\mathrm{pK}_{\mathrm{a} 1}$ associated with shortened linker length can be explained by an increased proximity of the second amide group to the initially deprotonated phenolate group as shown in Figure 4(b), which applies in both the unsubstituted and PEG-functionalized nLi-Me-3,2-HOPO ligands. Similarly, the drop in $\mathrm{pK}_{\mathrm{a} 1}$ upon PEG-functionalization is most likely caused by hydrogen bond donation from the PEG-amide nitrogen, as illustrated in Figure 4(c). This latter stabilization from the PEG-amide group in ligands $\mathbf{L}^{2} \mathbf{H}_{\mathbf{2}}-\mathbf{L}^{5} \mathbf{H}_{2}$, while unintended, can be considered roughly constant due to the identical location of the PEG-amide group in the linear backbone linkers. Thus, the electronic and geometric effects of linker length can be considered to be the prominent trend observed in titrations with PEG-nLi-Me-3,2-HOPO ligands.

The $\mathrm{pK}_{\mathrm{a}}$ values for ligands $\mathbf{L}^{6} \mathbf{H}_{\mathbf{2}}-\mathbf{L}^{\mathbf{8}} \mathbf{H}_{\mathbf{2}}$ cannot be compared against their PEG-free versions due to the latter's poor solubility in aqueous media. However, the PEG moiety in ligands $L^{6} \mathbf{H}_{2}$ and $\mathbf{L}^{7} \mathbf{H}_{2}$ is expected to have some inductive influence on proton affinity, since in free $\mathbf{L}^{6} \mathbf{H}_{\mathbf{2}}$ and $\mathbf{L}^{7} \mathbf{H}_{\mathbf{2}}$ the amide ${ }^{1} \mathrm{H}$ NMR resonances are shifted upfield by 0.29 ppm and $0.08 \mathrm{ppm}$, respectively, as compared to their unsubstituted analogs. ${ }^{[35]}$ This inductive influence is obviously much larger in $\mathbf{L}^{6} \mathbf{H}_{2}$ than in $\mathbf{L}^{7} \mathbf{H}_{2}$, but the steric consequences of 2,5-disubstitution on the thiophene linker are known to be significant, ${ }^{[43]}$ so the inductive effect is presumed to be of minor importance in ligand $\mathbf{L}^{6} \mathbf{H}_{2}$ upon uranyl chelation. In contrast, $\mathbf{L}^{8} \mathbf{H}_{\mathbf{2}}$ is expected to experience very little steric or electronic influences by PEG moiety inclusion, and indeed has a $\Sigma \mathrm{pK}_{\mathrm{a}}$ very similar to that of $\mathbf{L}^{5} \mathbf{H}_{\mathbf{2}}$, which is also an $n=5$ ligand.

Uranyl Titrations/Affinity. The uranyl affinities of ligands $\mathbf{L}^{2} \mathbf{H}_{\mathbf{2}}$ through $\mathbf{L}^{8} \mathbf{H}_{\mathbf{2}}$ were determined by performing spectrophotometric titrations. The poor solubility of the uranyl complexes necessitated $5 \mu \mathrm{M}$ analyte concentrations as well as a $5 \%$ starting DMSO concentration to assist in solvating the neutral uranyl complexes at neutral $\mathrm{pH}$. Unfortunately, uranyl titrations with ligands 2Li-Me-3,2-HOPO, 4Li-Me-3,2-HOPO, and $\mathbf{L}^{9} \mathbf{H}_{2}$ are impossible even at these low concentrations due to slow and reversible precipitation of a neutral $\mathrm{UO}_{2}(\mathrm{~L})($ solv.) species near neutral $\mathrm{pH}$. The bidentate ligand $\mathrm{Pr}$ Me-3,2-HOPO was found to be sufficiently soluble for spectrophotometric titrations at these concentrations. Metal-to-ligand ratios used in the titrations were those observed in the crystal structures of the uranyl complexes with unsubstituted Me-3,2-HOPO ligands, namely 1:1 for bis-Me-3,2-HOPO ligands and 1:2 for Pr-Me-3,2-HOPO. Three independent titrations were measured between $\mathrm{pH} 2.4$ and 11.0 except where reversibility analysis indicated a point in the titrations beyond which the complexes underwent an irreversible chemical change. Because the uranyl complexes routinely form below $\mathrm{pH} 4$, two strong acid titrations ( $\mathrm{pH} 3.0$ to 1.6) were carried out for each ligand. 
This is the post reviewed version of the following article: Szigethy, G. and Raymond, K. N. (2011), The Influence of Linker Geometry in Bis(3-hydroxy- $N$-methyl-pyridin-2-one) Ligands on Solution Phase Uranyl Affinity. Chemistry - A European Journal, 17: 1818-1827. doi: 10.1002/chem.201002372, which has been published in final form at http://onlinelibrary.wiley.com/doi/10.1002/chem.201002372

The uranyl titration spectra with PEG-substituted bis-Me-3,2-HOPO ligands generally exhibited similar absorption spectra in the range of $250-400 \mathrm{~nm}$, with a large absorption maximum in the $330-350 \mathrm{~nm}$ range, and often with a subtle shoulder at longer wavelengths. These absorption features closely resemble those of the free ligands, and are thus attributed to $\pi \rightarrow \pi^{*}$ transitions. Titrations with $\mathbf{L}^{6} \mathbf{H}_{2}$ exhibited the most unusual spectrum investigated, with a broad absorption feature in the $275-300 \mathrm{~nm}$ range, at which the other bis-Me-3,2-HOPO ligands display absorption minima. Independent of absorption features, however, absorption maxima with all ligands red shift upon increasing $\mathrm{pH}$, corresponding to deprotonation/metallation of the ligand. Although the uranyl complexes with bis-Me-3,2-HOPO ligands are red or orange in the solid state and in concentrated solution, no significant absorption transition was observed in wavelengths above $400 \mathrm{~nm}$ at $5 \mu \mathrm{M}$ concentrations.

Most uranyl titrations were reversible through the highest $\mathrm{pH}$ ranges of the titrations (typically $\mathrm{pH} 11.0-11.4$ ), indicating that no unforeseen chemical changes occur in the metal-ligand complex in solution (Figure 5). In contrast, titrations with fully-conjugated ligands $\mathbf{L}^{6} \mathbf{H}_{\mathbf{2}}$ and $\mathbf{L}^{7} \mathbf{H}_{\mathbf{2}}$ exhibited poor reversibility when titrations were taken to $\mathrm{pH} 11.0$ (Figure 5). It was found that running the titrations only up to $\mathrm{pH} 8.5$ and 9.0, respectively, restored reversibility in the uranyl titrations. The cause of this irreversibility is unknown, but corresponds roughly to additional deprotonation of or continued hydroxide introduction to the $\left[\mathrm{UO}_{2}(\mathrm{~L})(\mathrm{OH})\right]^{-}$complex to form a $\left[\mathrm{UO}_{2}(\mathrm{~L}) \mathrm{H}_{2}\right]^{2-}$ species (where $\mathrm{H}_{-1}$ represents hydroxide coordination or incremental complex deprotonation). To maintain consistency across the various bis-Me-3,2-HOPO ligands, titration data were truncated before the onset of the $\left[\mathrm{UO}_{2}\left(\mathrm{~L} \mathrm{H}_{2}\right]^{2-}\right.$ species. For most ligands, this data truncation occurred at about $\mathrm{pH}$ 9.0. Complete titration figures are provided in the Supporting Information.

Uranyl titrations with all Me-3,2-HOPO ligands displayed a rapid increase in intensity between $\mathrm{pH} 2$ and $\mathrm{pH} \mathrm{4}$, indicating deprotonation of the ligand and complexation of the uranyl cation. For tetradentate ligands (with the exception of $\mathbf{L}^{6} \mathbf{H}_{2}$ ), this result was refined as the formation of a $\mathrm{UO}_{2} \mathrm{~L}$ (solv.) complex. This assumption requires the simultaneous deprotonation of both Me-3,2-HOPO moieties, but is reasonable considering the similarity between $\mathrm{pK}_{\mathrm{a} 1}$ and $\mathrm{pK}_{\mathrm{a} 2}$ of these ligands and because uranyl chelation will drive deprotonation of a chelating ligand at lower $\mathrm{pH} .{ }^{[44]}$ The UVvisible spectra shifted again around neutral $\mathrm{pH}$, which was refined as the formation of a $\left[\mathrm{UO}_{2} \mathrm{~L}(\mathrm{OH})\right]^{-}$species (Scheme 2). This partial hydrolysis occurs near neutral $\mathrm{pH}$ because the fifth equatorial coordination position on the uranyl is known to be occupied by solvent in bis-Me-3,2-HOPO complexes, ${ }^{[35,36]}$ and thus hydroxide coordination does not necessitate ligand displacement. A similar partial hydrolysis event is observed in the uranyl complex with the potentially hexadentate desferrioxamine $\mathrm{B}$ (DFO), in which a $\left[\mathrm{UO}_{2}(\mathrm{DFO})(\mathrm{OH})\right]^{-}$complex was observed to form at neutral $\mathrm{pH} \cdot{ }^{[29]}$

Because 2,5-disubstituted thiophene-Me-3,2-HOPO ligands form dimeric $\left[\mathrm{UO}_{2}(\mathrm{~L})(\text { solv. })\right]_{2}$ complexes, ${ }^{[34]}$ such dimeric species were required in the refinement of titration data with $\mathbf{L}^{6} \mathbf{H}_{2}$. Refinement of the strong acid titration data was attempted two ways, assuming either that a mononuclear species $\left[\mathrm{UO}_{2}\left(\mathbf{L}^{6}\right) \mathrm{H}_{0 / 1}\right]^{0 /+}$ forms before a $\left[\mathrm{UO}_{2}\left(\mathbf{L}^{6}\right) \text { (solv.) }\right]_{2}$ dimer, or that the dimer forms in a concerted fashion, but only the latter strategy led to stable data refinement. This behavior suggests that the substitution on the 
This is the post reviewed version of the following article: Szigethy, G. and Raymond, K. N. (2011), The Influence of Linker Geometry in Bis(3-hydroxy- $N$-methyl-pyridin-2-one) Ligands on Solution Phase Uranyl Affinity. Chemistry - A European Journal, 17: 1818-1827. doi: 10.1002/chem.201002372, which has been published in final form at http://onlinelibrary.wiley.com/doi/10.1002/chem.201002372

thiophene ligand inhibits mononuclear complex formation even at the low concentrations used, which prior crystallographic studies led us to expect. ${ }^{[34]}$ Because both uranyl cations in the solid state $\left[\mathrm{UO}_{2}(\mathrm{~L})(\text { solv. })\right]_{2}$ dimer crystal structure displayed pentagonal planar coordination with one site occupied by solvent, the titration data were refined such that the $\left[\mathrm{UO}_{2}\left(\mathbf{L}^{6}\right)(\text { solv. })\right]_{2}$ dimer experiences two partial hydrolysis events, forming first a $\left\{\left[\mathrm{UO}_{2}\left(\mathbf{L}^{6}\right)(\text { solv. })\right]\left[\mathrm{UO}_{2}\left(\mathbf{L}^{6}\right)(\mathrm{OH})\right]\right\}^{-}$species, followed by a $\left\{\left[\mathrm{UO}_{2}\left(\mathbf{L}^{6}\right)(\mathrm{OH})\right]_{2}\right\}^{2-}$ species (Scheme 3). The onset of titration irreversibility at $\mathrm{pH} 8.0$ coincides with hydrolysis beyond the $\left\{\left[\mathrm{UO}_{2}\left(\mathbf{L}^{6}\right)(\mathrm{OH})\right]_{2}\right\}^{2-}$ species and is consistent with the onset of irreversibility in the uranyl titrations with $\mathbf{L}^{7} \mathbf{H}_{2}$ which was observed upon hydrolysis/deprotonation beyond the formation of the $\left[\mathrm{UO}_{2}\left(\mathbf{L}^{7}\right)(\mathrm{OH})\right]^{-}$species.

The speciation of uranyl complexes with bidentate $\mathbf{L}^{1} \mathbf{H}$ in solution are necessarily very different from those with $\mathbf{L}^{2} \mathbf{H}_{2}-\mathbf{L}^{\mathbf{8}} \mathbf{H}_{2}$. Because $\mathbf{L}^{1} \mathbf{H}$ has only one proton, $\mathbf{L}^{1}$ binds the uranyl cation at very low $\mathrm{pH}$ to first form a $\left[\mathrm{UO}_{2}\left(\mathbf{L}^{\mathbf{1}}\right)(\text { solv. })_{\mathrm{x}}\right]^{+}$complex which is the major species until $\mathrm{pH}$ 5.5, when the $\mathrm{UO}_{2}\left(\mathbf{L}^{1}\right)_{2}$ (solv.) complex observed in crystal structure analysis ${ }^{[36]}$ becomes the dominant species. This complex first undergoes the expected partial hydrolysis to form $\left[\mathrm{UO}_{2}\left(\mathbf{L}^{\mathbf{1}}\right)_{2}(\mathrm{OH})\right]^{-}$, then experiences one more hydrolysis below $\mathrm{pH} 10$. This last hydrolysis product could be refined as either a $\left[\mathrm{UO}_{2}\left(\mathbf{L}^{1}\right) \mathrm{H}_{-2}\right]^{-}$or $\left[\mathrm{UO}_{2}\left(\mathbf{L}^{1}\right)_{2} \mathrm{H}_{-2}\right]^{2-}$ species, with near negligible changes in the other formation constants. The former corresponds to displacement of one ligand upon coordination of a second hydroxide, while the latter corresponds to either deprotonation of a coordinated ligand or the introduction of hydroxide to the uranyl coordination plane without ligand displacement. The lack of acidic protons on coordinated Me-3,2-HOPO moieties rules out the possibility of additional deprotonation. However, the coordination of additional hydroxide would crowd the uranyl coordination plane, and the low concentrations and 1:2 $\mathrm{UO}_{2}: \mathbf{L}^{1} \mathbf{H}$ ratios used in the titrations suggest that ligand displacement to form a $\left[\mathrm{UO}_{2}\left(\mathbf{L}^{\mathbf{1}}\right)(\mathrm{OH})_{2}\right]^{-}$species at high $\mathrm{pH}$ is the more likely speciation in these titrations (Scheme 4).

Titration data analysis using the speciation models described above yielded the formation constants listed in Table 3. Because $\log \beta_{m l h}$ values are species dependent, with each ligand displaying different $\mathrm{pK}_{\mathrm{a}}$ values and uranyl complexation behavior, a speciesindependent method is needed to compare uranyl affinities. A metric frequently used for this purpose is that of $\mathrm{pM}$ (for this study $\mathrm{pUO}_{2}$ ) where $\mathrm{pUO}_{2}=-\log \left[\mathrm{UO}_{2}{ }^{2+}\right.$ free $]$, and " $\mathrm{UO}_{2}{ }^{2+}$ free" refers to solvated uranyl ion free of complexation by ligand or hydroxide. Using this metric, higher $\mathrm{pUO}_{2}$ values correspond to a lower concentration of uncomplexed uranyl in solution. $\mathrm{pUO}_{2}$ is calculated using standard conditions of $\left[\mathrm{UO}_{2}{ }^{2+}\right]$ $=10^{-6} \mathrm{M}$ and $[\mathrm{L}]=10^{-5} \mathrm{M}\left(\mathrm{L}: \mathrm{UO}_{2}{ }^{2+}=10\right)$, and thus the minimum $\mathrm{pUO}_{2}$ value is 6.0 , at which no metal complexation occurs. While typically reported at physiological $\mathrm{pH}, \mathrm{pUO}_{2}$ can be calculated at any $\mathrm{pH}$ once proton and uranyl affinities are known; $\mathrm{pUO}_{2}$ values at $\mathrm{pH} 2.5,7.4$ and 8.5 are listed for each Me-3,2-HOPO ligand in Table 4.

The $\mathrm{pUO}_{2}$ values in Table 4 reveal that the uranyl affinity of bis-HOPO ligands does indeed vary with changes in ligand geometry. However, the affinities do not follow gradual trends of the sort observecd in Table 2, where linker length and degree of conjugation affected ligand proton affinity in an incremental fashion. In contrast, small changes in linker length and geometry resulted in large changes in $\mathrm{pUO}_{2}$, with no noticeable correlation with the physical metrics gleaned from crystal structure 
This is the post reviewed version of the following article: Szigethy, G. and Raymond, K. N. (2011), The Influence of Linker Geometry in Bis(3-hydroxy- $N$-methyl-pyridin-2-one) Ligands on Solution Phase Uranyl Affinity. Chemistry - A European Journal, 17: 1818-1827. doi: 10.1002/chem.201002372, which has been published in final form at http://onlinelibrary.wiley.com/doi/10.1002/chem.201002372

analysis. ${ }^{[35]}$ Common to all ligands, however, is a dramatic rise in $\mathrm{pUO}_{2}$ (about $7 \mathrm{log}$ units) between $\mathrm{pH} 2.5$ and $\mathrm{pH}$ 7.4. It is not possible to credit this $\mathrm{pUO}_{2}$ increase entirely to a rise in ligand affinity, because concentrations of uranyl hydrolysis products $\left[\left(\mathrm{UO}_{2}\right)_{\mathrm{m}}(\mathrm{OH})_{\mathrm{n}}\right]^{(2 \mathrm{~m}-\mathrm{n})+}$ increase upon increased $\mathrm{pH}$, lowering $\left[\mathrm{UO}_{2}{ }^{2+}\right.$ free] independent of ligand identity or efficacy. However, because Me-3,2-HOPO ligands require deprotonation for metal chelation, it is reasonable to suspect that the majority of this rise in $\mathrm{pUO}_{2}$ comes from a change in ligand affinity upon complete deprotonation at higher $\mathrm{pH}$. This assumption is also supported by the UV-visible titration spectra, which exhibit significant shifts in $\lambda_{\max }$ and absorption intensity upon increasing $\mathrm{pH}$ from 2.5 to 7.4 , suggesting increased ligand chelation of the uranyl cation.

Focusing on ligands $\mathbf{L}^{2} \mathbf{H}_{2}-\mathbf{L}^{\mathbf{5}} \mathbf{H}_{2}$, there is no trend in uranyl affinity upon incremental increase in linker length at any $\mathrm{pH}$. Because ligand $\mathrm{pK}_{\mathrm{a}}$ decreases as linker length shortens, $\mathbf{L}^{2} \mathbf{H}_{\mathbf{2}}$ would be expected to bind most strongly to the uranyl cation. However, $\mathbf{L}^{2} \mathbf{H}_{2}$ displays the second highest affinity, with $\mathbf{L}^{4} \mathbf{H}_{2}$ displaying the strongest uranyl affinity at both low and high $\mathrm{pH} . \mathbf{L}^{4} \mathbf{H}_{\mathbf{2}}$ has a higher $\Sigma \mathrm{pK}$ a than both $\mathbf{L}^{\mathbf{2}} \mathbf{H}_{\mathbf{2}}$ and $\mathbf{L}^{3} \mathbf{H}_{2}$, so the observed uranyl affinity must be due to geometry effects. This high affinity is consistent with the relatively relaxed geometry observed in the $\mathrm{UO}_{2}(4 \mathrm{Li}-\mathrm{Me}-3,2-$ HOPO)(DMSO) crystal structure as well as with the superior ability for $4 \mathrm{Li}-\mathrm{Me}-3,2-$ HOPO to chelate actinides in vivo. ${ }^{[31,36]}$

Of the rigidly-linked ligands $\mathbf{L}^{6} \mathbf{H}_{2}-\mathbf{L}^{8} \mathbf{H}_{2}, \mathbf{L}^{6} \mathbf{H}_{\mathbf{2}}$ is the most acidic, and yet displays the poorest uranyl affinity at all $\mathrm{pH}$. This may be due to the inability to form monomeric uranyl complexes. The low $\mathrm{pUO}_{2}$ of $\mathbf{L}^{6} \mathbf{H}_{2}$ at higher $\mathrm{pH}$ is presumed to be a geometric effect caused by the amide rotation necessitated by substitution at the 2- and 5-positoins of the thiophene ring. ${ }^{[34]}$ Unfortunately, such distortions are unavoidable in solubilized 3,4-thiophene-Me-3,2-HOPO ligands, and whether similar uranyl affinities would be observed in geometrically similar, less sterically-congested, N-substituted 3,4-pyrroleMe-3,2-HOPO ligands remains a question for future study.

Ligand $\mathbf{L}^{7} \mathbf{H}_{2}$ shows the most favorable $\mathrm{pUO}_{2}$ of the rigidly-linked ligands, approaching that of $\mathbf{L}^{4} \mathbf{H}_{2}$. Because minor $\mathrm{pK}_{\mathrm{a}}$ changes are apparently not a significant factor in determining uranyl affinity in bis-Me-3,2-HOPO ligands, this affinity is presumably due to a favorable geometric agreement between the ligand and the uranyl coordination preferences. The $\mathrm{pUO}_{2}$ of $\mathbf{L}^{7} \mathbf{H}_{\mathbf{2}}$ is also higher than that of $\mathbf{L}^{2} \mathbf{H}_{\mathbf{2}}$ (both $n=2$ ), indicating that ligand rigidity and appropriate preorganization favor high uranyl affinity, as expected. In contrast, the $\mathrm{pUO}_{2}$ of $\mathbf{L}^{\mathbf{8}} \mathbf{H}_{2}$ is significantly lower, despite the favorable conformational parameters observed in crystal structures of the unsubstituted $\mathrm{UO}_{2}(m$-xyMe-3,2-HOPO)(DMF) structure. ${ }^{[35]}$

The high $\mathrm{pUO}_{2}$ of $\mathbf{L}{ }^{1} \mathbf{H}$, which rivals that of $\mathbf{L}^{4} \mathbf{H}_{2}$ at $\mathrm{pH} 2.5$ and $\mathbf{L}^{2} \mathbf{H}_{2}$ at high $\mathrm{pH}$, can be understood by considering that uranyl chelation by $\mathbf{L}^{1} \mathbf{H}$ at low $\mathrm{pH}$ requires a single deprotonation event, while chelation of bis-Me-3,2-HOPO ligands requires two, making $\left(\mathbf{L}^{1}\right)^{-}$coordination relatively favorable at low $\mathrm{pH}$. At high $\mathrm{pH}$, the speciation model with $\mathbf{L}^{1} \mathbf{H}$ also reveals that the relatively high affinity is accompanied by ligand displacement in favor of hydroxide ion. Thus, although $\mathbf{L}^{1} \mathbf{H}$ exhibits a high $\mathrm{pUO}_{2}$, the individual PrMe-3,2-HOPO ligands display significantly less affinity towards the uranyl cation than the bis-Me-3,2-HOPO ligands, as the chelate effect would lead one to expect. 
This is the post reviewed version of the following article: Szigethy, G. and Raymond, K. N. (2011), The Influence of Linker Geometry in Bis(3-hydroxy- $N$-methyl-pyridin-2-one) Ligands on Solution Phase Uranyl Affinity. Chemistry - A European Journal, 17: 1818-1827. doi: 10.1002/chem.201002372, which has been published in final form at http://onlinelibrary.wiley.com/doi/10.1002/chem.201002372

\section{Conclusions}

Seven PEG-substituted bis-Me-3,2-HOPO ligands were synthesized as water-soluble, structural analogs to ligands subjected to prior crystallographic analysis. ${ }^{[35,36]}$ Solution thermodynamic measurements demonstrated that linker length and geometry have a measurable effect on the proton affinity of bis-Me-3,2-HOPO ligands, but that uranyl affinity of these ligands does not correlate with trends in proton affinity. Significantly, the PEG-4Li-Me-3,2-HOPO ligand $\mathbf{L}^{4} \mathbf{H}_{2}$ bound most strongly to the uranyl cation, which supports earlier observations from in vivo chelation studies and crystallographic studies. ${ }^{[32,36]}$ The $o$-phenylene linker in $\mathbf{L}^{7} \mathbf{H}_{\mathbf{2}}$ imparted the second highest uranyl affinity, rivaling that of $\mathbf{L}^{4} \mathbf{H}_{2}$, and had a higher affinity than the similarly-sized $\mathbf{L}^{2} \mathbf{H}_{2}$. Because these results are generally independent of ligand acidity, it can be concluded that ligand geometry imparted by the linker structure (and perhaps ligand preorganization in the case of $\left.\mathbf{L}^{7} \mathbf{H}_{2}\right)$ is responsible for the observed uranyl affinities.

One aspect the uranyl titrations and the resultant $\mathrm{pUO}_{2}$ values described above do not address is the matter of selectivity. In most applications associated with biological removal of actinides, high binding constants are necessary, but high selectivity is also desirable if an administered drug is to be effective. Such selectivity is also necessary in industrial extraction processes, so further evaluation of bis-Me-3,2-HOPO ligands will require titration measurements against biologically relevant ions such as $\mathrm{Ca}^{2+}$ and $\mathrm{Zn}^{2+}$, as well as other actinides.

\section{Experimental Section}

Titration Solutions and Equipment. Corning high performance combination glass electrodes (response to $\left[\mathrm{H}^{+}\right]$was calibrated before each titration ${ }^{[45]}$ ) were used together with either an Accumet $\mathrm{pH}$ meter or a Metrohm Titrino to measure the $\mathrm{pH}$ of the experimental solutions. Metrohm autoburets (Dosimat or Titrino) were used for incremental additions of acid or base standard solution to the titration cell. The titration instruments were fully automated and controlled using LabVIEW software. ${ }^{[46]}$ Titrations were performed in $0.1 \mathrm{M} \mathrm{KCl}$ supporting electrolyte under positive Ar gas pressure. The temperature of the experimental solution was maintained at $25{ }^{\circ} \mathrm{C}$ by an externally circulating water bath. UV-visible spectra for incremental titrations were recorded on a Hewlett-Packard 8452a spectrophotometer (diode array). Solid reagents were weighed on a Metrohm analytical balance accurate to $0.01 \mathrm{mg}$. All titration solutions were prepared using distilled water that was purified by passing through a Millipore Milli-Q reverse osmosis cartridge system and degassed by boiling for $1 \mathrm{~h}$ while being purged under Ar. Carbonate-free $0.1 \mathrm{M} \mathrm{KOH}$ was prepared from Baker Dilut-It concentrate and was standardized by titrating against potassium hydrogen phthalate using phenolphthalein as an indicator. Solutions of $0.1 \mathrm{M} \mathrm{HCl}$ were similarly prepared and were standardized by titrating against sodium tetraborate decahydrate to Methyl Red endpoint. Ligand stock solutions were made by dissolving a weighed amount of ligand accurate to $0.01 \mathrm{mg}$ in DMSO in a volumetric flask. These stock solutions were frozen when not in use to prevent ligand decomposition. A stock uranyl solution in $1.2 \mathrm{wt} \%$ nitric acid was

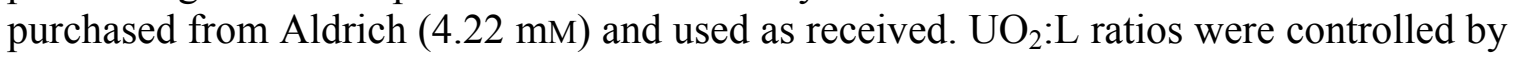
careful addition of uranyl and ligand solutions to the titration vessel. 
This is the post reviewed version of the following article: Szigethy, G. and Raymond, K. N. (2011), The Influence of Linker Geometry in Bis(3-hydroxy- $N$-methyl-pyridin-2-one) Ligands on Solution Phase Uranyl Affinity. Chemistry - A European Journal, 17: 1818-1827. doi: 10.1002/chem.201002372, which has been published in final form at http://onlinelibrary.wiley.com/doi/10.1002/chem.201002372

Spectrophotometric and Potentiometric Titrations: All titrations were performed with about 5\% starting concentration of DMSO added to the $\mathrm{KCl}$ solution to promote the solvation of protonated ligands and their neutral uranyl complexes. Spectrophotometric titrations were carried out in the presence of 10-20 equivalents (as compared to ligand concentration) of $\mathrm{NH}_{4} \mathrm{Cl}$, MES, and HEPES buffers in order to dampen the $\mathrm{pH}$ change between incremental additions of titrant. Each addition of acid or base was followed by an equilibration period before $\mathrm{pH}$ and absorbance data were collected. For potentiometric titrations this delay was 300 seconds and for spectrophotometric titrations was 600 seconds for free ligand and 600-1200 seconds for titrations in the presence of $\mathrm{UO}_{2}{ }^{2+}$. Spectra were recorded between 250-550 nm. The UV-silent region above $420 \mathrm{~nm}$ was monitored for baseline drift as an indication of precipitated material.

Potentiometric titrations were carried out at 150-200 $\mu \mathrm{M}$ ligand concentrations. Spectrophotometric titrations for protonation constants of 2Li-Me-3,2-HOPO and 4LiMe-3,2-HOPO were carried out at about $50 \mu \mathrm{M}$ ligand concentrations using a titration cell with a $1 \mathrm{~cm}$ path length quartz cuvette attached. Spectrophotometric titrations for uranyl affinity were performed at about $6 \mu \mathrm{M}$ complex concentration using a $6.6 \mathrm{~cm}$ path length quartz-windowed titration cell. All mid-pH titrations were repeated a minimum of three times and were run forwards and backwards (from acid to base and reverse) within limits set by the reversibility of the titration.

Spectrophotometric uranyl titrations of $\mathbf{L}^{2} \mathbf{H}_{2}-\mathbf{L}^{8} \mathbf{H}_{2}$ were performed at approximately $5 \mu \mathrm{M}$ concentrations using a $6.6 \mathrm{~cm}$ path length quartz-windowed titration cell with a 5\% starting DMSO concentration necessary for complete salvation of neutral uranyl species near neutral $\mathrm{pH}$. Three independent titrations, each consisting of a forward (acid to base) and reverse (base to acid) titration, were measured between $\mathrm{pH} 2.4$ and 11.0 except where reversibility analysis indicated a point in the titrations beyond which the complexes underwent an irreversible chemical change. Low $\mathrm{pH}$ titrations were performed from $\mathrm{pH} 3$ down to $\mathrm{pH}$ 1.6, and electrodes were calibrated as described in a previous publication. ${ }^{[4]}$

Titration Data Treatment: Potentiometric data were analyzed using Hyperquad ${ }^{[48,}$ 49] software. The data from at least three independent titrations, each consisting of one forward $(\mathrm{pH} 3$ to $\mathrm{pH} 10)$ and one reverse $(\mathrm{pH} 10$ to $\mathrm{pH} 3)$ titration were analyzed separately. These analyses resulted in similar values, so were refined together to provide better fit statistics. Spectrophotometric titration data were analyzed using the program pHab. ${ }^{[50]}$ Data from three independent titrations consisting of one forward and one reverse titration were analyzed separately, with the forward and backward runs refined separately. Both analysis programs utilized nonlinear least squares regression to determine formation constants.

Values for the hydrolysis product of the uranyl cation were taken from a recent literature publication. ${ }^{[51]}$ Wavelengths between $250-400 \mathrm{~nm}$ were typically used for data refinement of spectrophotometric titrations. The number of absorbing species to be refined upon was determined by factor analysis within the pHab program suite. ${ }^{[50]}$ Reversibility of spectrophotometric titrations was determined by comparison of the species- and concentration-independent value $A^{*} v$ (absorbance*volume) at selected wavelengths for the forward and reverse titrations. Speciation diagrams were generated using HYSS2 ${ }^{[52,53]}$ titration simulation software and the protonation and metal complex 
This is the post reviewed version of the following article: Szigethy, G. and Raymond, K. N. (2011), The Influence of Linker Geometry in Bis(3-hydroxy- $N$-methyl-pyridin-2-one) Ligands on Solution Phase Uranyl Affinity. Chemistry - A European Journal, 17: 1818-1827. doi: 10.1002/chem.201002372, which has been published in final form at http://onlinelibrary.wiley.com/doi/10.1002/chem.201002372

formation constants were determined by potentiometric and spectrophotometric titration experiments.

Acknowledgement. We would like to thank Drs. Rebecca Abergel and Trisha Hoette for assistance with the titrations measurement and data treatment. This research is supported by the Director, Office of Science, Office of Basic Energy Sciences, and the Division of Chemical Sciences, Geosciences, and Biosciences of the U.S. Department of Energy at LBNL under Contract No. DE-AC02-05CH11231.

[1] This paper is \#62 in the series "Specific Sequestering Agents for the Actinides." For the previous paper, see reference number 35.

[2] É. Ansoborlo, B. Amekraz, C. Moulin, V. Moulin, F. Taran, T. Bailly, R. Burgada, M.-H. Hengé-Napoli, A. Jeanson, C. Den Auwer, L. Bonin, P. Moisy, C. R. Chemie 2007, 10, 1010-1019.

[3] S. I. Müller, M. Valdebenito, K. Hantke, Biometals 2009, 22, 691-695.

[4] M. A. Fischbach, H. Lin, D. R. Liu, C. T. Walsh, Nature Chem. Bio. 2006, 2, $132-$ 138.

[5] O. Andersen, Chem. Rev. 1999, 99, 2683-2710.

[6] D. F. Back, É. Bonfada, M. Manzoni de Oliveira, E. S. Lang, J. Inorg. Biochem. 2007, 101, 709-714.

[7] M. D. Cappellini, P. Patoneri, Annu. Rev. Med. 2009, 60, 25-38.

[8] R. C. Hider, Biochem. Soc. Trans. 2002, 30, 751-754.

[9] G. J. Kontoghiorghes, K. Neocleous, A. Kolnagou, Drug Safety 2003, 26, 553584.

[10] J. Maynadié, J.-C. Berthet, P. Thuery, M. Ephritikhine, Chem. Comm. 2007, 486488.

[11] J.-C. Berthet, P. Thuery, J.-P. Dognon, D. Guillaneux, M. Ephritikhine, Inorg. Chem., 47, 6850-62.

[12] C. J. Burns, D. L. Clark, R. J. Donohoe, P. B. Duval, B. L. Scott, C. D. Tait, Inorg. Chem. 2000, 39, 5464-5468.

[13] N. N. Rammo, K. R. Hamid, T. K. Ibrahim, J. Alloys. Compd. 1994, 210, 319324.

[14] M. J. Sarsfield, M. Helliwell, J. Raftery, Inorg. Chem. 2004, 43, 3170-3179.

[15] D. H. Templeton, A. Zalkin, H. Ruben, L. K. Templeton, Acta Cryst. C 1985, C41, 1439-1441.

[16] P. Thuéry, B. Masci, M. Takimoto, T. Yamato, Inorg. Chem. Comm. 2007, 10, 795-799.

[17] W. Zhang, J. Zhao, Inorg. Chem. Comm. 2006, 9, 397-399.

[18] B. Masci, P. Thuéry, Cryst. Eng. Comm. 2007, 9, 582-590.

[19] J. A. Danis, M. R. Lin, B. L. Scott, B. W. Eichhorn, W. H. Runde, Inorg. Chem. 2001, 40, 3389-3394.

[20] P. Thuéry, B. Masci, J. Chem. Soc. Dalton Trans. 2003, 2411-2417.

[21] I. Grenthe, J. Drozdzynski, T. Fujino, E. C. Buck, T. E. Albrecht-Schmitt, S. F. Wolf, in The Chemistry of the Actinide and Transactinide Elements, Vol. $1,3^{\text {rd }}$ ed. 
This is the post reviewed version of the following article: Szigethy, G. and Raymond, K. N. (2011), The Influence of Linker Geometry in Bis(3-hydroxy- $N$-methyl-pyridin-2-one) Ligands on Solution Phase Uranyl Affinity. Chemistry - A European Journal, 17: 1818-1827. doi: 10.1002/chem.201002372, which has been published in final form at http://onlinelibrary.wiley.com/doi/10.1002/chem.201002372

(Eds.: L. R. Morss, N. M. Edelstein, J. Fuger), Springer, Dordrecht, The Netherlands, 2006, pp. 253-698.

[22] J. L. Sessler, D. Seidel, A. E. Vivian, V. Lynch, B. L. Scott, D. W. Keogh, Angew. Chem. Int. Ed. 2001, 40, 591-594.

[23] T. S. Franczyk, K. R. Czerwinski, K. N. Raymond, J. Am. Chem. Soc. 1992, 114, 8138-8146.

[24] P. H. Walton, K. N. Raymond, Inorg. Chim. Acta. 1995, 240, 593-601.

[25] P. L. Arnold, A. J. Blake, C. Wilson, J. B. Love, Inorg. Chem. 2004, 43, 82068208.

[26] P. L. Arnold, D. Patel, A. J. Blake, C. Wilson, J. B. Love, J. Am. Chem. Soc. 2006, 128, 9610-9611.

[27] J. N. Mathur, M. S. Murali, K. L. Nash, Solv. Extr. Ion Exch. 2001, 19, 357-390.

[28] A. P. Paiva, P. Malik, J. Radioanal. Nucl. Chem. 2004, 261, 485-496.

[29] L. Mullen, C. Gong, K. R. Czerwinski, J. Rad. Nucl. Chem. 2007, 273, 683-688.

[30] P. W. Durbin, Health Phys. 2008, 95, 465-492.

[31] P. W. Durbin, B. Kullgren, S. N. Ebbe, J. Xu, K. N. Raymond, Health Phys. 2000, 78, 511-521.

[32] P. W. Durbin, B. Kullgren, K. N. Raymond, Rad. Prot. Dosim. 1998, 79, 433-443.

[33] A. E. V. Gorden, J. Xu, K. N. Raymond, Chem. Rev. 2003, 103, 4207-4282.

[34] G. Szigethy, K. N. Raymond, Inorg. Chem. 2009, 48, 11489-11491.

[35] G. Szigethy, K. N. Raymond, Inorg. Chem. 2010, 49, 6755-6765.

[36] J. Xu, K. N. Raymond, Inorg. Chem. 1999, 38, 308-315.

[37] P. Thuéry, N. Keller, M. Lance, J. D. Figner, M. Nierlich, New J. Chem. 1995, 19, 619-625.

[38] T. M. Garrett, M. E. Cass, K. N. Raymond, J. Coord. Chem. 1992, 25, 241-253.

[39] A. D'Aléo, J. Xu, E. G. Moore, C. J. Jocher, K. N. Raymond, Inorg. Chem. 2008, 47, 6109-6111.

[40] (Ed.: N. R. Council), National Research Council, Washington, DC, 2000, p. 142.

[41] (Ed.: N. R. Council), National Research Council, Washington, DC, 2001, p. 198.

[42] J. Xu, P. W. Durbin, B. Kullgren, K. N. Raymond, J. Med. Chem. 1995, 38, 26062614.

[43] G. Szigethy, K. N. Raymond, Inorg. Chem. 2009, 48, 11489-91.

[44] Z. Szabó, I. Grenthe, Inorg. Chem. 2000, 39, 5036-5043.

[45] P. Gans, B. O'Sullivan, Talanta 2000, 51, 33-37.

[46] LABVIEW, version 8.0; National Instruments Corp.: 11500 N Mopac Expwy, Austin, TX 78759-3504.

[47] A. R. Johnson, B. O'Sullivan, K. N. Raymond, Inorg. Chem. 2000, 39, 26522660.

[48] P. Gans, A. Sabatini, A. Vacca, Talanta 1996, 43, 1739-1753.

[49] P. Gans, A. Sabatini, A. Vacca, HYPERQUAD2003; University of Leed and University of Florence: Leeds, U.K., and Florence, Italy, 2003.

[50] P. Gans, A. Sabatini, A. Vacca, Annali Di Chimica 1999, 89, 45-49.

[51] P. L. Brown, Radiochimica Acta 2002, 90, 589-93.

[52] L. Alderighi, P. Gans, A. Ienco, D. Peters, A. Sabatini, A. Vacca, Coord. Chem. Rev. 1999, 184, 311-318. 
This is the post reviewed version of the following article: Szigethy, G. and Raymond, K. N. (2011), The Influence of Linker Geometry in Bis(3-hydroxy- $N$-methyl-pyridin-2-one) Ligands on Solution Phase Uranyl Affinity. Chemistry - A European Journal, 17: 1818-1827. doi: 10.1002/chem.201002372, which has been published in final form at http://onlinelibrary.wiley.com/doi/10.1002/chem.201002372

\section{Scheme and Figure Legends:}

Figure 1. Mono- and bis-bidentate Me-3,2-HOPO ligands previously studied. ${ }^{[34-36]}$

Figure 2. Water-soluble bis-Me-3,2-HOPO ligands.

Figure 3. Ligand $\mathrm{L}^{9} \mathbf{H}_{2}$ and two views of the crystal structure of its uranyl complex $\mathrm{UO}_{2}\left(\mathbf{L}^{9}\right)(\mathrm{DMSO})$. Thermal ellipsoids are drawn at the $50 \%$ probability level. Hydrogen atoms and non-coordinating solvent are omitted for clarity. Oxygen atoms are red, carbons gray, nitrogens blue, sulfur yellow, and uranium silver.

Figure 4. Intramolecular stabilization of deprotonated Me-3,2-HOPO ligands.

Figure 5. Representative reversibilities of uranyl titrations with bis-Me-3,2-HOPO ligands through pH 11: $\mathbf{L}^{3} \mathbf{H}_{2}$, (left, reversible) and $\mathbf{L}^{6} \mathbf{H}_{\mathbf{2}}$, (right, irreversible).

Scheme 1. Intramolecular hydrogen bonding in bis-Me-3,2-HOPO ligands upon deprotonation/metalation.

Scheme 2. Formation of a $\left[\mathrm{UO}_{2} \mathrm{~L}(\mathrm{OH})\right]^{-}$species. Uranyl oxo atoms are omitted for clarity.

Scheme 3. Proposed speciation of uranyl titrations with $\mathbf{L}^{6} \mathbf{H}_{2}$. Uranyl oxo atoms are omitted for clarity.

Scheme 4. Proposed speciation of uranyl titrations with $\mathbf{L}^{\mathbf{1}} \mathbf{H}_{\mathbf{2}}$. Uranyl oxo atoms are omitted for clarity.

Table 1. Crystallographic parameters for $\mathrm{UO}_{2}\left(\mathbf{L}^{9}\right)(\mathrm{DMSO})$.

\begin{tabular}{|c|c|c|c|}
\hline Formula & $\mathrm{C}_{28} \mathrm{H}_{34} \mathrm{~N}_{4} \mathrm{O}_{11} \mathrm{SU} \cdot 1 / 4 \mathrm{H}_{2} \mathrm{O}$ & Cryst. size $\left[\mathrm{mm}^{3}\right]$ & $0.35 \times 0.10 \times 0.05$ \\
\hline MW & 877.19 & $T[\mathbf{K}]$ & $115(2)$ \\
\hline Crystal system & Orthorhombic & $Z$ & 8 \\
\hline Space group & Pbca & $\rho_{\text {calcd }}\left[\mathrm{g} \cdot \mathrm{cm}^{-3}\right]$ & 1.923 \\
\hline Habit & Plate & $\mu_{\text {palcd }}\left[\mathrm{mm}^{-1}\right]$ & 5.494 \\
\hline Color & Red & $\theta_{\min }, \theta_{\max },\left[^{\circ}\right]$ & $3.29,26.36$ \\
\hline$a[\AA ̊]$ & $13.451(2)$ & Total reflections & 27837 \\
\hline$b[\AA]$ & $15.839(2)$ & Data/ restr./ param. & $5978 / 0 / 410$ \\
\hline$c[\AA]$ & $28.445(4)$ & $F(000)$ & 3428 \\
\hline$\alpha\left[^{\circ}\right]$ & 90 & $\mathbf{T}_{\min } / \mathbf{T}_{\max }$ & 0.324 \\
\hline$\beta\left[^{\circ}\right]$ & 90 & $\mathrm{R} 1[I>2 \sigma(I)]^{[\mathrm{a}]}$ & 0.0304 \\
\hline$\gamma\left[^{\circ}\right]$ & 90 & wR2(all data) $^{[\mathrm{a}]}$ & 0.0738 \\
\hline$V\left[\AA^{3}\right]$ & $6060.3(16)$ & GOF $^{[\mathrm{a}]}$ & 1.040 \\
\hline
\end{tabular}


This is the post reviewed version of the following article: Szigethy, G. and Raymond, K. N. (2011), The Influence of Linker Geometry in Bis(3-hydroxy- $N$-methyl-pyridin-2-one) Ligands on Solution Phase Uranyl Affinity. Chemistry - A European Journal, 17: 1818-1827. doi: 10.1002/chem.201002372, which has been published in final form at http://onlinelibrary.wiley.com/doi/10.1002/chem.201002372

Table 2. $\mathrm{pK}_{\mathrm{a}}$ values of bis-Me-3,2-HOPO ligands.

\begin{tabular}{ccccc}
\hline Ligand & $\boldsymbol{n}^{[\mathrm{a}]}$ & $\mathbf{p K}_{\mathbf{a} 1}$ & $\mathbf{p K _ { \mathbf { a } 2 }}$ & $\mathbf{\Sigma} \mathbf{p K _ { \mathbf { a } }}$ \\
\hline $\mathbf{L}^{\mathbf{1}} \mathbf{H}$ & -- & $6.12^{[42]}$ & -- & -- \\
2Li-Me-3,2-HOPO & 2 & $5.82(3)$ & $6.68(3)$ & $12.50(4)$ \\
4Li-Me-3,2-HOPO & 4 & $6.01(1)$ & $7.02(4)$ & $13.03(4)$ \\
$\mathbf{L}^{\mathbf{2}} \mathbf{H}_{\mathbf{2}}$ & 2 & $5.10(6)$ & $6.45(1)$ & $11.55(6)$ \\
$\mathbf{L}^{\mathbf{3}} \mathbf{H}_{\mathbf{2}}$ & 3 & $5.37(2)$ & $6.72(2)$ & $12.09(3)$ \\
$\mathbf{L}^{\mathbf{4}} \mathbf{H}_{\mathbf{2}}$ & 4 & $5.25(4)$ & $6.60(3)$ & $11.85(5)$ \\
$\mathbf{L}^{\mathbf{5}} \mathbf{H}_{\mathbf{2}}$ & 5 & $5.52(7)$ & $6.75(2)$ & $12.27(7)$ \\
$\mathbf{L}^{\mathbf{6}} \mathbf{H}_{\mathbf{2}}$ & 2 & $4.91(8)$ & $6.22(1)$ & $11.13(8)$ \\
$\mathbf{L}^{\mathbf{7}} \mathbf{H}_{\mathbf{2}}$ & 2 & $5.09(3)$ & $6.29(1)$ & $11.38(3)$ \\
$\mathbf{L}^{\mathbf{8}} \mathbf{H}_{\mathbf{2}}$ & 5 & $5.70(6)$ & $6.75(2)$ & $12.45(6)$ \\
\hline
\end{tabular}

${ }^{[\mathrm{a}]} n=$ number of carbon atoms between amide nitrogens.

Table 3. Log $\beta_{m l h}$ values for uranyl titrations with Me-3,2-HOPO ligands.

\begin{tabular}{|c|c|c|c|c|c|c|c|c|}
\hline Ligand & $\log \beta_{11-2}$ & $\log \beta_{11-1}$ & $\log \beta_{110}$ & $\log \beta_{12-1}$ & $\log \beta_{120}$ & $\log \beta_{22-1}$ & $\log \beta_{22-1}$ & $\log \beta_{220}$ \\
\hline $\mathbf{L}^{1} \mathbf{H}^{[\mathrm{a}]}$ & $-2.50(6)$ & & $10.64(3)$ & $11.48(4)$ & $17.91(2)$ & & & \\
\hline $\mathbf{L}^{2} \mathbf{H}_{2}$ & & $6.30(8)$ & $12.5(1)$ & & & & & \\
\hline $\mathbf{L}^{3} \mathbf{H}_{2}$ & & $5.86(6)$ & $12.6(1)$ & & & & & \\
\hline $\mathbf{L}^{4} \mathbf{H}_{2}$ & & $6.97(6)$ & $13.9(1)$ & & & & & \\
\hline $\mathbf{L}^{5} \mathbf{H}_{2}$ & & $5.64(4)$ & $13.42(7)$ & & & & & \\
\hline $\mathbf{L}^{6} \mathbf{H}_{2}{ }^{[\mathrm{a}]}$ & & & & & & $15.74(5)$ & $22.47(8)$ & $28.1(1)$ \\
\hline $\mathbf{L}^{7} \mathbf{H}_{2}$ & & $6.6(1)$ & $13.04(1)$ & & & & & \\
\hline $\mathbf{L}^{8} \mathbf{H}_{2}{ }^{[\mathbf{a}]}$ & & $5.38(5)$ & $12.89(1)$ & & & & & \\
\hline
\end{tabular}

[a] In addition to low $\mathrm{pH}$ data (pH 3 to $\mathrm{pH} 1.6$ ), only forward (acid to base) titration data was used due to observed irreversibility

Table 4. Calculated $\mathrm{pUO}_{2}$ values for Me-3,2-HOPO ligands.

\begin{tabular}{cccc}
\hline \multirow{2}{*}{ Ligand } & \multicolumn{3}{c}{$\mathbf{p U O}_{\mathbf{2}}{ }^{[\mathrm{a}]}$} \\
\cline { 2 - 4 } & $\mathbf{p H ~ 2 . 5}$ & $\mathbf{p H ~ 7 . 4}$ & $\mathbf{p H ~ 8 . 5}$ \\
\hline $\mathbf{L}^{\mathbf{1}} \mathbf{H}$ & $7.98(3)$ & $14.70(4)$ & $15.96(3)$ \\
$\mathbf{L}^{\mathbf{2}} \mathbf{H}_{\mathbf{2}}$ & $7.0(1)$ & $14.63(8)$ & $15.75(8)$ \\
$\mathbf{L}^{3} \mathbf{H}_{\mathbf{2}}$ & $6.6(1)$ & $14.24(7)$ & $15.34(6)$ \\
$\mathbf{L}^{4} \mathbf{H}_{\mathbf{2}}$ & $8.0(1)$ & $15.39(7)$ & $16.43(9)$ \\
$\mathbf{L}^{5} \mathbf{H}_{\mathbf{2}}$ & $7.1(1)$ & $14.44(6)$ & $15.16(4)$ \\
$\mathbf{L}^{6} \mathbf{H}_{\mathbf{2}}$ & $6.01(1)$ & $13.39(3)$ & $14.48(2)$ \\
$\mathbf{L}^{7} \mathbf{H}_{\mathbf{2}}$ & $7.62(4)$ & $14.97(9)$ & $16.1(1)$ \\
$\mathbf{L}^{8} \mathbf{H}_{\mathbf{2}}$ & $6.55(6)$ & $14.00(3)$ & $14.87(5)$ \\
\hline${ }^{[\mathrm{a} \mid} \mathrm{pUO}_{2}=-\log \left[\mathrm{UO}_{2}{ }^{2+}\right.$ free $],\left[\mathrm{UO}_{2}{ }^{2+}\right]=1 \mu \mathrm{M},[\mathrm{L}]=10 \mu \mathrm{M}$
\end{tabular}

\section{TOC Text:}

Catch Phrase: Bis-Me-3,2-HOPO Uranyl Affinity

Text: Seven water-soluble, tetradentate, bis-Me-3,2-HOPO ligands were synthesized and their affinity for the uranyl cation determined by solution phase titrations. The butyllinked ligand exhibits the greatest uranyl affinity at all $\mathrm{pH}$, with the rigid o-phenylenelinked ligand displaying the next highest affinity of the ligands investigated. No discernable trends in uranyl affinity could be identified in relation to linker length or geometry. 
This is the post reviewed version of the following article: Szigethy, G. and Raymond, K. N. (2011), The Influence of Linker Geometry in Bis(3-hydroxy- $N$-methyl-pyridin-2-one) Ligands on Solution Phase

Uranyl Affinity. Chemistry - A European Journal, 17: 1818-1827. doi: 10.1002/chem.201002372, which has been published in final form at http://onlinelibrary.wiley.com/doi/10.1002/chem.201002372

Keywords: Uranium, Ligand effects, Speciation, Thermodynamics, Titrations 
This is the post reviewed version of the following article: Szigethy, G. and Raymond, K. N. (2011), The Influence of Linker Geometry in Bis(3-hydroxy- $N$-methyl-pyridin-2-one) Ligands on Solution Phase Uranyl Affinity. Chemistry - A European Journal, 17: 1818-1827. doi: 10.1002/chem.201002372, which has been published in final form at http://onlinelibrary.wiley.com/doi/10.1002/chem.201002372<smiles>CCCNC(=O)c1ccn(C(C)P)c(=O)c1O</smiles>

$\mathrm{R}=-\left(\mathrm{CH}_{2}\right)_{\mathrm{n}}$<smiles>Cc1cscc1C#N</smiles><smiles>Cn1ccc(C(=O)NC(C)(C)C)c(O)c1=O</smiles>
bis-Me-3,2-HOPO

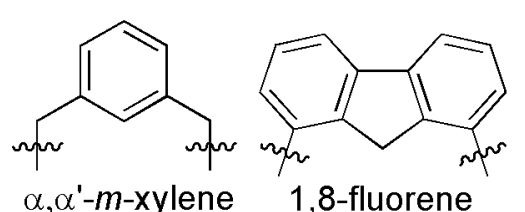

1,8-fluorene<smiles></smiles>

Figure 1

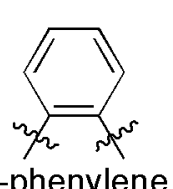

3,4-thiophene o-phenylene $\alpha, \alpha^{\prime}-m$-xylene 
This is the post reviewed version of the following article: Szigethy, G. and Raymond, K. N. (2011), The Influence of Linker Geometry in Bis(3-hydroxy- $N$-methyl-pyridin-2-one) Ligands on Solution Phase Uranyl Affinity. Chemistry - A European Journal, 17: 1818-1827. doi: 10.1002/chem.201002372, which has been published in final form at http://onlinelibrary.wiley.com/doi/10.1002/chem.201002372

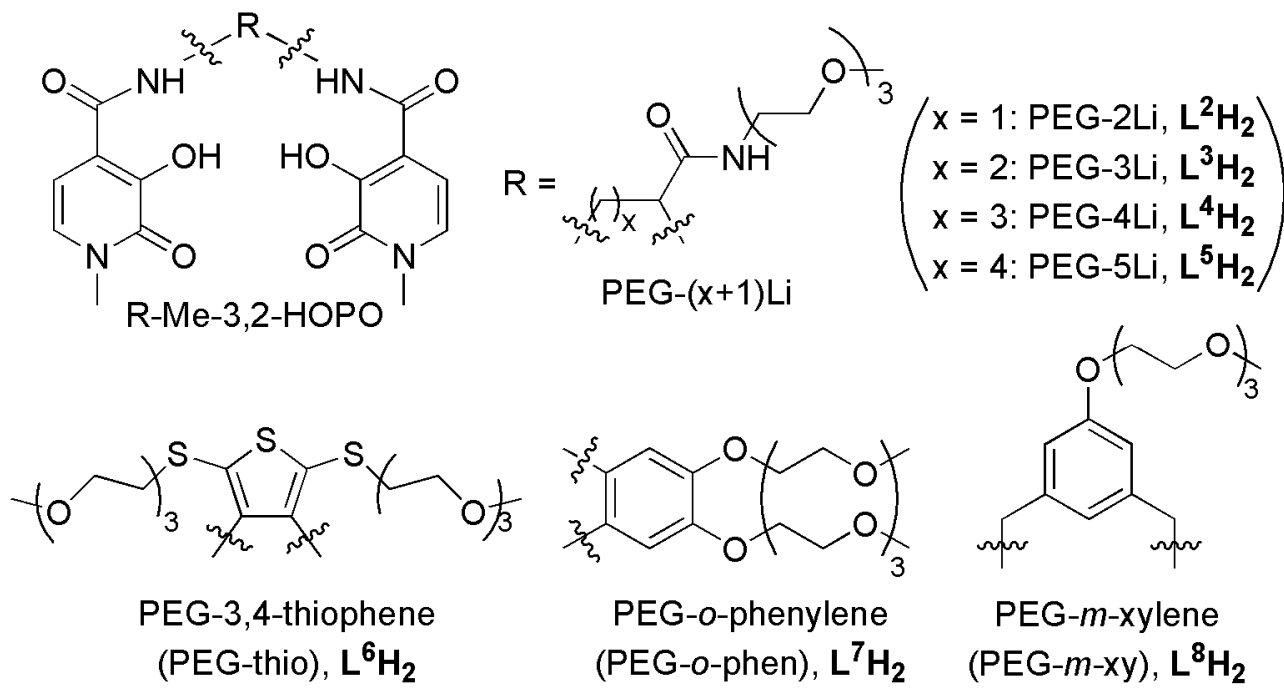

Figure 2 
This is the post reviewed version of the following article: Szigethy, G. and Raymond, K. N. (2011), The Influence of Linker Geometry in Bis(3-hydroxy- $N$-methyl-pyridin-2-one) Ligands on Solution Phase Uranyl Affinity. Chemistry - A European Journal, 17: 1818-1827. doi: 10.1002/chem.201002372, which has been published in final form at http://onlinelibrary.wiley.com/doi/10.1002/chem.201002372

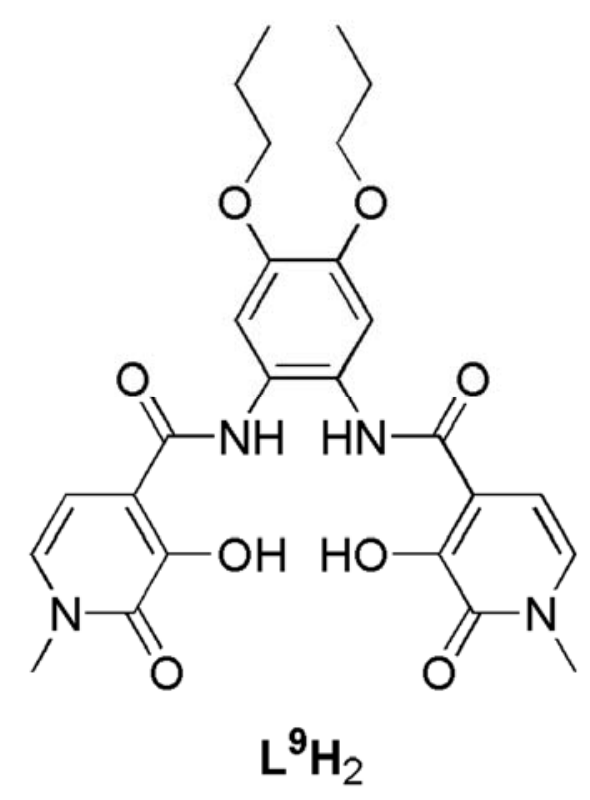

Figure 3

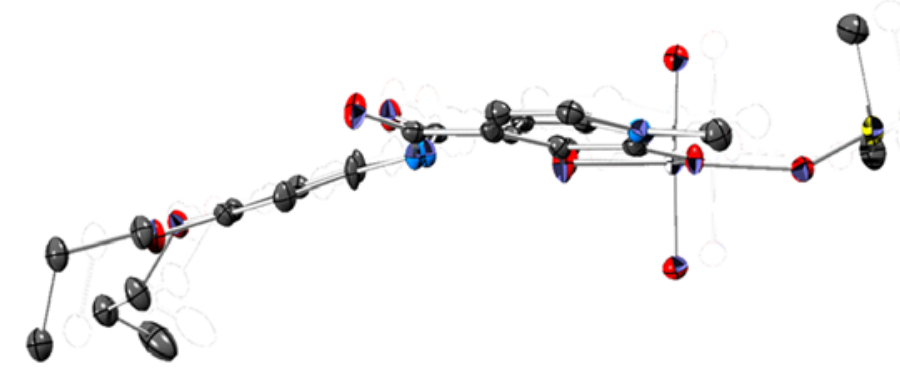


This is the post reviewed version of the following article: Szigethy, G. and Raymond, K. N. (2011), The Influence of Linker Geometry in Bis(3-hydroxy- $N$-methyl-pyridin-2-one) Ligands on Solution Phase Uranyl Affinity. Chemistry - A European Journal, 17: 1818-1827. doi: 10.1002/chem.201002372, which has been published in final form at http://onlinelibrary.wiley.com/doi/10.1002/chem.201002372<smiles>[R]N1C(=O)c2ccn(C)c(=O)c2O[C@H]([OH2+])[C@@H]1OC</smiles>

(a)

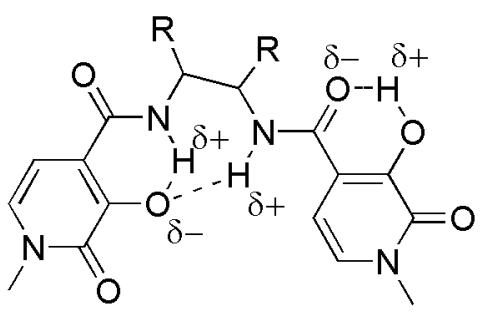

(b)

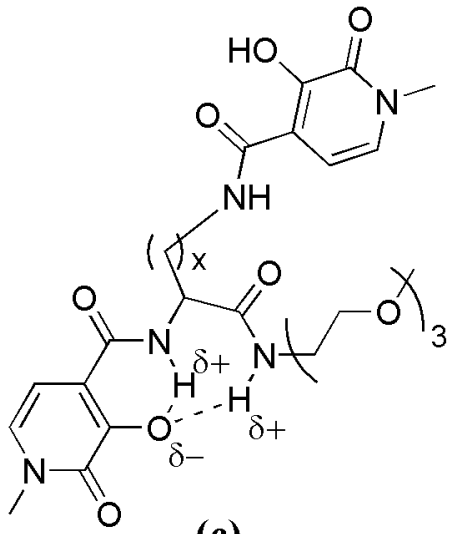

(c)

Figure 4 
This is the post reviewed version of the following article: Szigethy, G. and Raymond, K. N. (2011), The Influence of Linker Geometry in Bis(3-hydroxy- $N$-methyl-pyridin-2-one) Ligands on Solution Phase Uranyl Affinity. Chemistry - A European Journal, 17: 1818-1827. doi: 10.1002/chem.201002372, which has been published in final form at http://onlinelibrary.wiley.com/doi/10.1002/chem.201002372

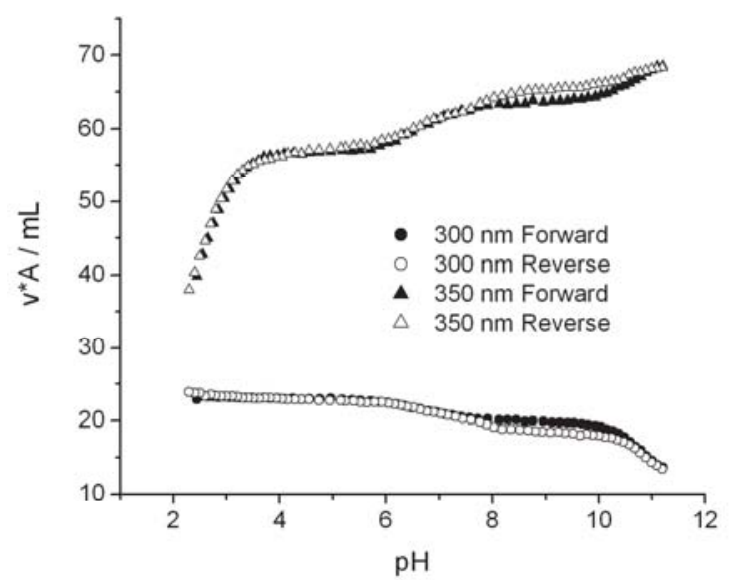

(a)

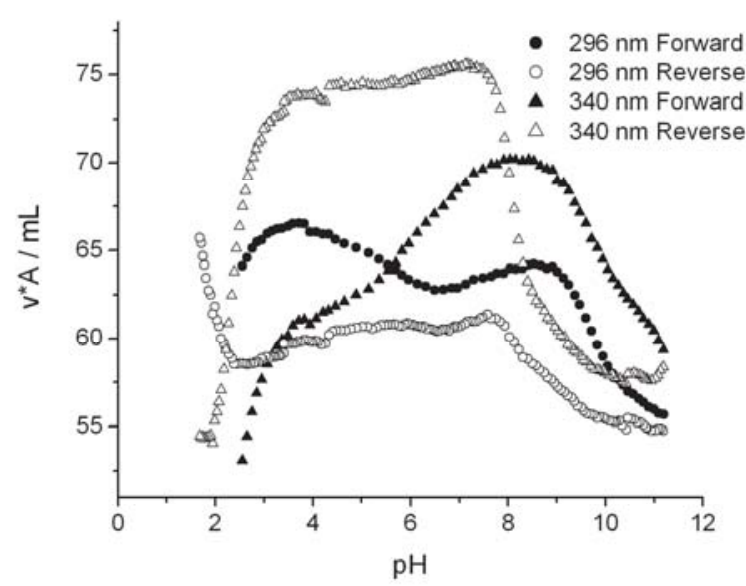

(b)

Figure 5 
This is the post reviewed version of the following article: Szigethy, G. and Raymond, K. N. (2011), The Influence of Linker Geometry in Bis(3-hydroxy- $N$-methyl-pyridin-2-one) Ligands on Solution Phase Uranyl Affinity. Chemistry - A European Journal, 17: 1818-1827. doi: 10.1002/chem.201002372, which has been published in final form at http://onlinelibrary.wiley.com/doi/10.1002/chem.201002372

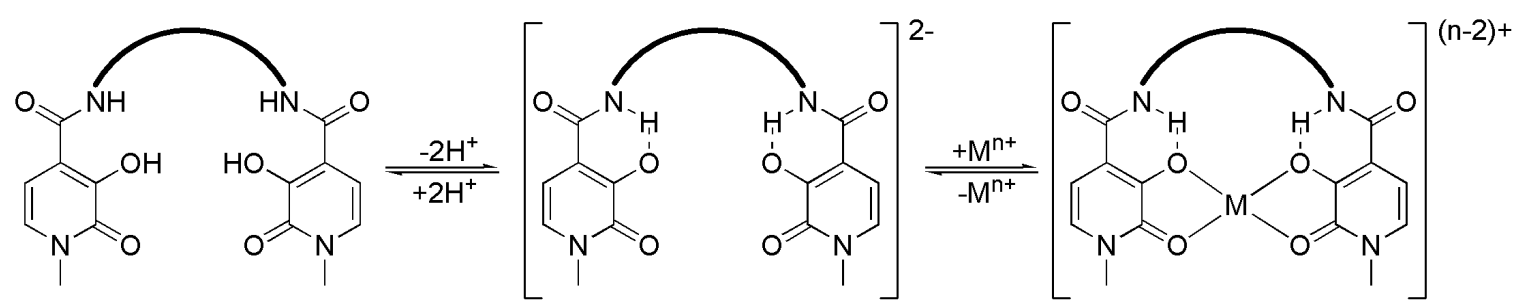

\section{Scheme 1}


This is the post reviewed version of the following article: Szigethy, G. and Raymond, K. N. (2011), The Influence of Linker Geometry in Bis(3-hydroxy- $N$-methyl-pyridin-2-one) Ligands on Solution Phase Uranyl Affinity. Chemistry - A European Journal, 17: 1818-1827. doi: 10.1002/chem.201002372, which has been published in final form at http://onlinelibrary.wiley.com/doi/10.1002/chem.201002372
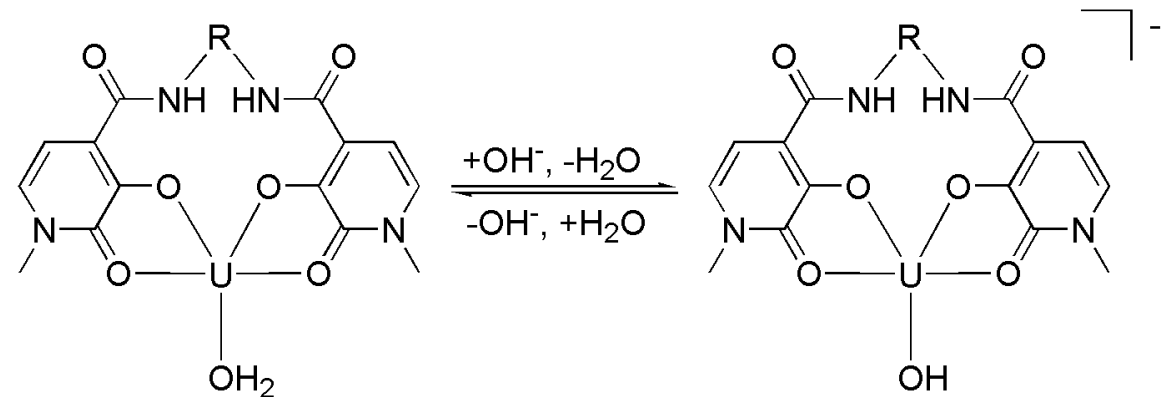

Scheme 2 
This is the post reviewed version of the following article: Szigethy, G. and Raymond, K. N. (2011), The Influence of Linker Geometry in Bis(3-hydroxy- $N$-methyl-pyridin-2-one) Ligands on Solution Phase Uranyl Affinity. Chemistry - A European Journal, 17: 1818-1827. doi: 10.1002/chem.201002372, which has been published in final form at http://onlinelibrary.wiley.com/doi/10.1002/chem.201002372

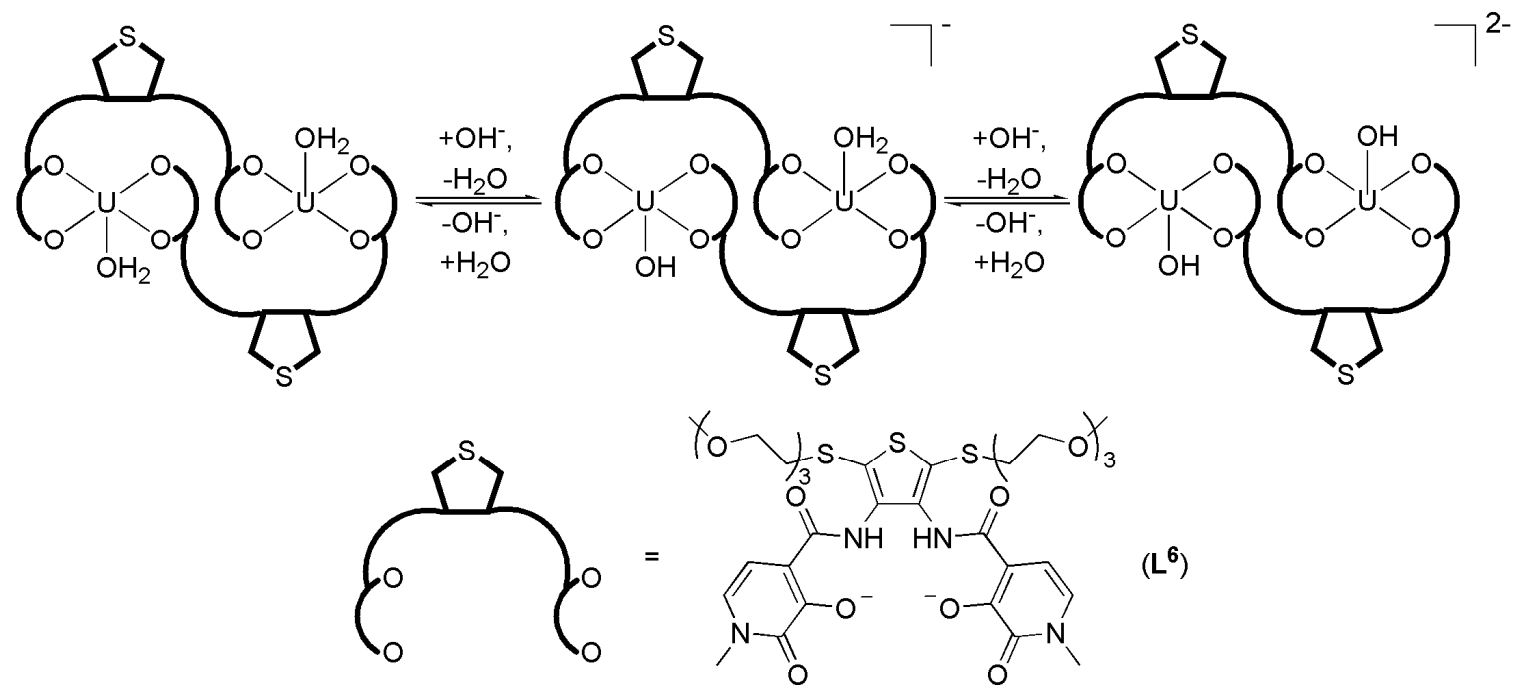

Scheme 3 
This is the post reviewed version of the following article: Szigethy, G. and Raymond, K. N. (2011), The Influence of Linker Geometry in Bis(3-hydroxy- $N$-methyl-pyridin-2-one) Ligands on Solution Phase Uranyl Affinity. Chemistry - A European Journal, 17: 1818-1827. doi: 10.1002/chem.201002372, which has been published in final form at http://onlinelibrary.wiley.com/doi/10.1002/chem.201002372

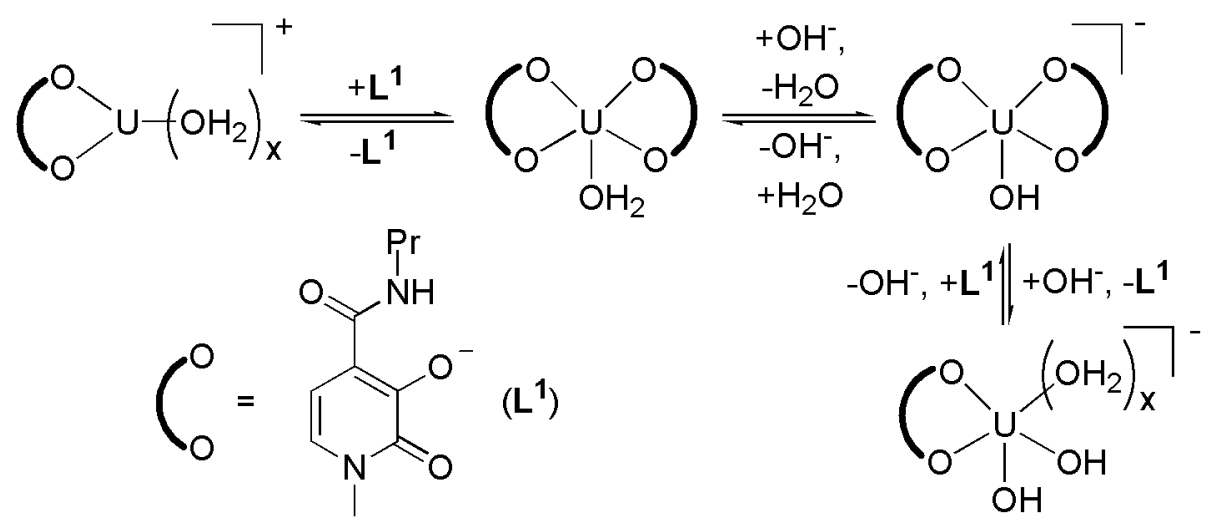

Scheme 4 


\section{LEGAL DISCLAIMER}

This document was prepared as an account of work sponsored by the United States Government. While this document is believed to contain correct information, neither the United States Government nor any agency thereof, nor The Regents of the University of California, nor any of their employees, makes any warranty, express or implied, or assumes any legal responsibility for the accuracy, completeness, or usefulness of any information, apparatus, product, or process disclosed, or represents that its use would not infringe privately owned rights. Reference herein to any specific commercial product, process, or service by its trade name, trademark, manufacturer, or otherwise, does not necessarily constitute or imply its endorsement, recommendation, or favoring by the United States Government or any agency thereof, or The Regents of the University of California. The views and opinions of authors expressed herein do not necessarily state or reflect those of the United States Government or any agency thereof or The Regents of the University of California. 